Occupational therapists are challenged to demonstrate how their practice is informed by evidence of effectiveness. In the absence of evidence from scientific investigation, theories are used to frame judgements about clinical situations. This paper explores how the process of adapting a kitchen can be informed by occupational theories, based on the first author's experiences as a social services occupational therapist. The kitchen is a familiar space in occupational therapy and forms a key environment for meeting nutritional and social needs in the domestic setting.

The process of altering a kitchen is used to illustrate concepts associated with occupation in everyday life. Issues arising from two kitchen adaptations are investigated using categories from the Canadian Model of Occupational Performance and the definition of therapeutic occupation (Nelson 1996). The limitations of applying theory to practice are explored, alongside analysis of how theory enhances practice. Finally, a synthesis, of knowledge based on science and creative practice based on art, is proposed.

\title{
What's Cooking? Theory and Practice in the Kitchen
}

\author{
Wendy Bryant and Elizabeth McKay
}

\section{Introduction}

In seeking evidence to support practice, occupational therapists can be confronted by the lack or the seeming irrelevance of published studies. Where proof of the effectiveness of particular interventions is not available (which, it could be argued, is the case for much of occupational therapy), the theory base offers some guidance for practice (McColl 2003). This paper aims to demonstrate that theories emerging from occupational science are, in fact, not a poor alternative to hard scientific evidence, but a rich means of developing understanding and, as a result, improving practice itself. Similarly, practice can shape emerging theories to ensure their validity and meaningfulness for the occupational therapy profession. The process of clinical reasoning thus becomes not just a means of justifying decisions, but of extending each therapeutic story for both personal and professional development.

By grounding this paper in an area of practice, that of adapting a kitchen, theories can be explored in an accessible way. This paper works from an exploration of the kitchen as an occupational space, to the impact of the wider context and, finally, to the process of therapy. It could be argued that person-centred practice demands that the focus of attention should always start from the service user; however, focusing on the area of practice is a process of pattern matching or finding similarities and differences. This facilitates awareness of personal and professional knowledge and values (Mattingly and Fleming 1994, Bolton 2001). In this paper, three scenarios involving kitchen adaptations and alterations have been included, working from the personal to assessment issues to intervention issues. One is drawn from personal experience and two are based on professional experience as a social services occupational therapist.

\section{The kitchen as an occupational space}

Theories underpinning occupational therapy emphasise how occupation can promote health and how human life is motivated to act to ensure continued survival (Reilly 1962, Wilcock 1998, Yerxa 2000). It is easy to devalue this knowledge in a familiar setting, such as the kitchen. Making a cup of tea does not have the same status as heart surgery in western health care, probably because of the perceived professional skills required to undertake heart surgery in contrast to the mundane and everyday activities that take place in a kitchen. Yet routine assessment and treatment in occupational therapy involves observing people as they prepare and consume food and drink, cook and clear up. These occupations are critical for continued health and survival: the physiological need for food and fluids is only one aspect of why people seek to spend time in a kitchen. Theories illuminating the complex interaction between the person, the occupation and the environment can help to identify the wider reasons for being in a kitchen (Stewart and Law 2003).

Why define a kitchen as an occupational space: is it not enough just to call it a kitchen? It can be hard to sustain interest in familiar everyday environments. Yet occupational 
theories seek to emphasise the importance of the environment in enabling occupation (Rigby and Letts 2003). Occupational therapists have often substituted the word 'occupation' with 'purposeful activity' and 'activity'. An investigation of these terms by Golledge (1998) suggested that there was overlap and inconsistency in the use of the words by different authors and proposed that there was a difference between them. Occupations are environmentspecific and embody individual meanings and roles. Purposeful activities are less rooted in specific contexts and reflect a therapeutic purpose rather than individualised meaning. Finally, 'activities' are remote from the service user's priority for change. Golledge (1998) seemed to suggest that occupational therapists should focus on an occupation's potential for change from the perspective of the individual service user.

More recently, Creek (2003) has proposed a hierarchy of words associated with doing, ranging from skills to occupations. From this perspective, the kitchen becomes an occupational space, where any number of skills are required to carry out a great range of occupations. Understanding this widens the scope of occupational therapy and ensures that individual differences are acknowledged. A kitchen assessment can then include whatever a person might want to do in a kitchen that promotes his or her health and wellbeing.

Earlier, Creek (1998) pointed out that each person, whether therapist, service user or carer, will determine the purpose of an occupation for himself or herself, stating that activity is voluntary, triggered by an 'intrinsic motivation to be active' and governed by choice. So an individual will choose to be involved in an occupation and will find it meaningful for personal reasons. The kitchen may not be an attractive space for someone who ascribes negative meanings to food, for instance when living with an eating disorder or even on a temporary attempt to lose weight. Although the levels of awareness of those personal meanings would be specific to the individual's cognitive and affective state, the recognition in occupational theory that each occupation holds different meanings for individuals has great implications for practice (Creek 1998, Hasselkus 2002, Polgar and Landry 2004).

Yet pressures on resources prevent occupational therapists from shifting the focus of their kitchen assessments beyond the need to assess safety and ability to self-care. In practice, there are serious constraints on practitioners and the minimisation of both symptoms and risk is paramount. In the context of major adaptations to a kitchen, a detailed examination of how the kitchen will be used as an occupational space is required, not only to justify funding the adaptation but also to ensure that the changes will benefit all those using the kitchen on a regular basis. An ill-informed adaptation could, for example, exacerbate access problems, place additional strain on carers and have an impact on the occupational performance of individuals in the long term. Stark (2003) argued that ensuring that intervention is tailored to meet the occupational goals of the service user is essential when adapting the environment.
Setting these goals in the context of the resources available to both therapist and service user ensures that a sustainable and realistic plan can be made.

Analysing factors having an impact on occupational performance need not be a process limited to professional life. In her work on reflective practice, Bolton (2001) has advocated recognition and acknowledgement of personal and private perspectives alongside professional views. For this paper, reflecting on the process of redesigning my own kitchen enabled me to discover some of the multiple meanings involved and the impact of the environment on my own occupational performance and that of my family. At the time of the kitchen alteration, my professional role as a social services occupational therapist informed the process. Subsequently, investigating occupational theory has reinforced understandings that seemed marginal at first glance.

\section{Changing rooms}

The kitchen in our house was removed and a new one created in the dining room. The old kitchen, stripped of cupboards, sink, cooker and washing machine, was furnished with the piano, a computer and books and became a study. The dining room, with new kitchen units and a door to the garden, became a kitchen diner. Every mealtime, since my first child had begun to sit in a high chair, I had been planning this change for our home.

The provision of separate rooms for eating and food preparation, acceptable in the prevailing culture of formal mealtimes when our house was built in the 1930s, now seemed deliberately to create extra work for me as a working mother with small children. I dreamed of eliminating the trips from kitchen to dining room and imagined the new kitchen table as a place not just to eat but also to relax and socialise with friends and family. Analysis of what was going to happen in the kitchen was required to facilitate the best design. Flexibility was important in order to accommodate changes over time. Occupations in the new kitchen had multiple meanings, ranging from the anticipated convenience of reconfiguring the living space to the creation of a central hub for family activity.

Having space in our new kitchen to sit enabled more than one activity to take place at once. We could cook food and supervise the children drawing at the same time. New opportunities emerged, many of which were not obvious until we started to use the new room. For example, the kitchen was now the largest room with a hard floor surface. Pushing the table to one side to clean the floor spontaneously created a new space, where the children danced and enjoyed sliding on the floor.

Hocking (2000), in her examination of the findings of occupational science, pointed out how engagement in occupation can, in itself, generate new meanings at a personal level. Occupation involves the use of time, which is influenced by previous experience and, in turn, influences how time is used in the future. She analysed the process of moving vegetables from a board to a soup pot to illustrate the dynamic processes in occupation. There are interactions between each aspect which have an impact on the significance and performance of the activity.

Can the details ever really be pinned down and is it a useful process? Primeau (1996), in a criticism of the tendency for researchers to divide occupation into component parts, 
highlighted how categories could reflect imposed values more than the real experience of individuals. She pointed out that the traditional categories used by occupational therapists of work, leisure and self-care could not be applied to household work, being unpaid and a duty as well as involving the care of others. More contemporary classifications of occupation have accommodated these criticisms.

Harvey and Pentland (2004) have proposed four categories: necessary, contracted, committed and free time. Returning to my kitchen and applying these categories shows how occupational theory can support a fuller understanding. Necessary occupations are those that we do to ensure continued physiological survival, for example preparing and eating food in the kitchen. Contracted occupations are those that generate regular income: the new kitchen, with room for a table, provided a space for working at home. Committed occupations do not typically attract a salary or fixed hours, but nevertheless involve significant time. The kitchen, redesigned to facilitate simultaneous supervision of children and food preparation, enabled me to dedicate time to necessary and committed occupations in a more time-efficient way. I was always hopeful that by doing this, I would have more free time for occupations of my choosing. Harvey and Pentland (2004), however, were careful to highlight that free-time occupations could include those occupations that carried social obligations rather than arising from physiological necessity. Perhaps the writing of thank you letters for birthday presents could be seen in this light, although it is possible that the term 'free-time occupation' would be resented by my children.

None of these categories, however, seems to capture how occupation promotes health in the way that Ruskin (1907/2000) did. He summed up the benefits of occupation to humanity as follows:

When men are rightly occupied, their amusement grows out of their work, as colour-petals out of a fruitful flower; when they are faithfully helpful and compassionate, all their emotions become steady, deep, perpetual and vivifying to the soul, as the natural pulse to the body (p60).

\section{Beyond the personal: science and assessment}

Ruskin (1907/2000) predated the modern emphasis in health care on the systematic management of illness. He recognised the relationship between occupations, health and the environment, redesigning his home to promote his health, yet the link with kitchen adaptations in social services occupational therapy can seem tenuous. The shift from a focus on managing disease to one on minimising disability has generated a new theory base for occupational therapists (Stewart and Law 2003). Occupational science has arisen from a perceived need for occupational therapists to move beyond the medical model and reclaim the original impetus for the birth of the profession (Reilly 1962). The work of Whiteford (2000) on occupational deprivation showed how occupational theories could be developed both from research and through practice. Her studies of prisoners and occupation led to the definition of occupational deprivation as being 'a state of preclusion from engagement in occupations of necessity and/or meaning due to factors that stand outside the immediate control of the individual' (Whiteford 2000, p201).

Rather than changing the individual to fit the environment, Whiteford (2000) acknowledged the importance of the environment in depriving individuals of opportunity for meaningful occupation. This definition appears to arise from a similar concept to that of the social model, which stresses the need for change in the environment rather than in the functioning of people with disabilities. The social model highlights how discriminatory practice arises from the medical model and its associated concepts of normality and abnormality (Oliver 1999, Campbell 2002, Tregaskis 2002). Shifting emphasis from trying to put people right with drugs and surgery, the social model proposes that adapting the public and domestic environments will accommodate a wider range of needs. Occupational deprivation and the social model, both theories concerned with facilitating occupation, clearly justify and inform kitchen adaptations, as shown in the illustration below.

\section{What's cooking?}

'Fran's' kitchen was large in space, but largely inaccessible to her. The cupboard doors had small ledges instead of handles and were impossible for her to grip and open. The process of adaptation involved the usual complications of grant funding and the attendant limitations on what could be funded. In the United Kingdom, the Disabled Facilities Grant is designed to provide funding for accessible facilities for a person with disabilities in his or her home setting. A kitchen can be complicated, because often the facilities are used by more than one person. Fran shared the use of her kitchen with her husband, her adult daughter and a long-term lodger.

Fran was small in build and her ability to reach and stand for any length of time was restricted by extensive rheumatoid arthritis. Her requirements for physically accessible facilities were very different from those of her husband and her lodger, who were both very tall. Solutions such as electric adjustable-height cupboards and sink were considered, but resisted. Fran's husband had long-term mental health problems and her daughter was also experiencing regular episodes of psychosis. Change in this kitchen had to be planned very carefully and Fran's daughter moved out during this time, creating a mixed sense of relief and anxiety for Fran and her husband.

The task of creating a central space in their home, which accommodated all the family's requirements, was overwhelming. Compromises were found. There was enough space in the kitchen to create lower storage spaces accessible to Fran and the controls for the taps were located at the front of the sink, well within her reach. The new fridge had a door that rolled out like a large drawer, making the depths of the fridge accessible at last. The new kitchen greatly reduced the difficulties for Fran in fulfilling her wish to prepare food for herself and her husband without help. 
In Fran's kitchen adaptation, careful balancing of the needs of all household members was required. The impact of the changes on the other family members was important in order to ensure that they did not become deprived of the kitchen as an occupational space. Fran, being unable to do what she wanted to do in the kitchen, was occupationally deprived until the new kitchen was complete. The complexity of Fran's situation is not unusual. Communicating the significance of the details is challenging and many dimensions of a person's life have to be included, especially where changes to the domestic environment are required. There is rarely one problem with only one solution.

The pressure of waiting lists has forced occupational therapy in United Kingdom social services to become primarily focused on issues of personal independence in self-care. Life beyond the immediate domestic setting cannot be considered in detail for every person, other than to ensure that the individual has access to weekday activities if required and has means of getting food and money. The emphasis is on physical disability and the provision of equipment or adaptations to compensate for loss of function arising from the disability (Community Occupational Therapy Services 1999). This is despite occupational therapists being uniquely positioned to offer not only holistic assessments but also holistic interventions. Could theory help to support occupational therapists to articulate the meaning of their interventions beyond purely physical rehabilitation and safety issues?

Fran's kitchen is analysed retrospectively here, using the Canadian Model of Occupational Performance (CMOP), as described by the Canadian Association of Occupational Therapists (CAOT 1997) (see Fig. 1), to structure the analysis. Central to the model is the person, comprising physical, cognitive and affective functions, with spirituality at the core. In the process of planning the adaptation to Fran's kitchen, many factors beyond her physical pain and limitation in movement were considered. A recurrent theme emerged in discussions, expressing her belief that the kitchen was a space for social contact and emotional

\section{Fig. 1. The Canadian Model of Occupational Performance.}

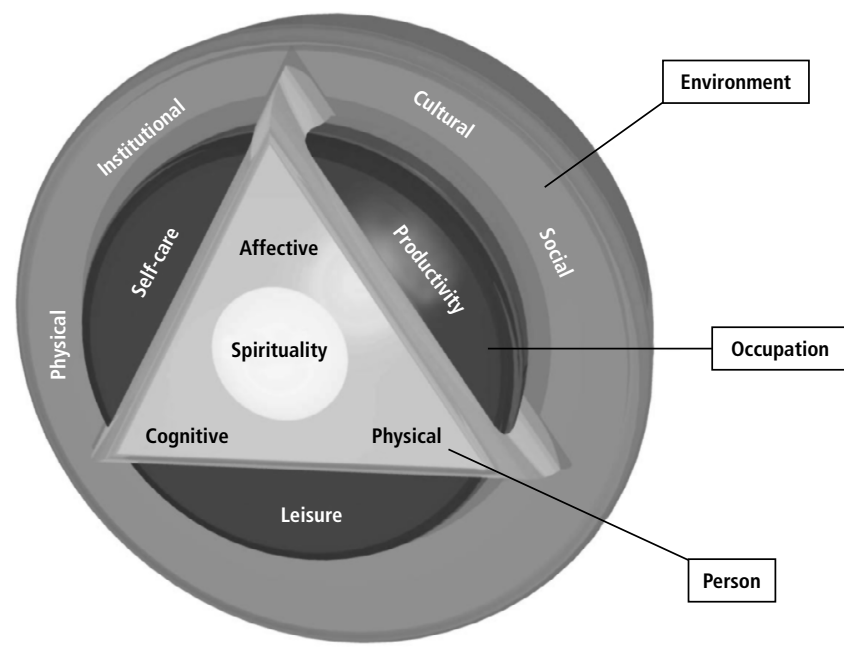

Source: Reproduced from Enabling Occupation: An Occupational Therapy Perspective, (C) 1997 with permission of CAOT Publications ACE. support. Potential adaptations were evaluated from this perspective as much as from the physical ease of access, which was the original reason for seeking adaptation. The person is represented in CMOP by a triangle, which intersects with a circle rather like an upturned jam-jar lid, representing the environment. Four different aspects of the environment are represented:

1. Physical: For example, Fran's kitchen had a very small step at the internal doorway, which was eliminated by incorporating a very slight ramp.

2. Institutional: For example, the whole process of the adaptation was conducted within the confines of statutory provision. From an early point in the assessment, the need for grant funding was established.

3. Cultural: For example, preparation of fresh food was an important occupation for Fran. This could be seen as a reflection of contemporary concern with healthy diets and the safety of food.

4. Social: For example, Fran's chosen role as meal provider was considered alongside the needs of the other people resident in the house.

The space between the person (the triangle) and the environment (the circle) is where occupation is situated. It is placed here because 'occupation occurs in the interaction between persons and their environment' (CAOT 1997). Occupation is split into self-care, productivity and leisure and it is tempting to speculate whether there would be any effect if these terms were altered to Harvey and Pentland's (2004) terms of necessary, contracted, committed and free-time occupations. Whatever terms are used, defining occupation in terms of its purpose enables the acknowledgement of issues beyond physiological survival. Over time, a continuing assessment of Fran's occupations in terms of who she was and the environment she lived in would enable specific and individually appropriate adaptations to be designed and modified as new information emerged.

What goes on in many domestic kitchens can be seen as a microcosm of human occupation. The preparation and consumption of food, although primarily an activity aimed at physiological survival, is heavy with meaning, individually and culturally. Use of the CMOP can assist in the process of determining meanings. Food is essential for physiological survival and so the preparation and consumption of food is routinely investigated by occupational therapists in many settings (Porter et al 1998). Identifying the reason for the assessment, that is, the meaning of the assessment and its significance to the individual, is essential. But do the models created by occupational scientists help occupational therapists when working with people in kitchens beyond assessment? When a situation becomes static and change is hard to implement, how do occupational theories help then?

\section{Science and intervention}

Investigating the process of therapy rather than the domain of concern of an occupational therapist can generate theories 
that inform interventions. Traditionally, theories about therapeutic processes have been predominantly psychological, concerned with the individual's motivation to change. Analysing how elements of occupation alter in response to change over time is the focus of Nelson's (1996) definition of therapeutic occupation. Nelson (1996) sees the occupational therapist as a facilitator, synthesising information and generating new challenges, but in a very practical sense.

\section{'This kitchen is driving me crazy'}

'This kitchen is driving me crazy' was the sort of thing that 'Patricia' would say. Sadly, for her, the organisational priorities for adaptations were focused on access to toilet and bedroom facilities, and the fact that she could physically stand up in the kitchen and make a hot drink and snack for herself made her low priority for attention. Patricia had recently moved to the house, a council-owned property, and the kitchen had been previously used by a very tall, single man. Being a very short, young grandmother with chronic back pain which radiated down her legs, much of the kitchen was physically inaccessible to her.

Despite her pain, she was anxious to maintain her role as provider of food: for her husband, who worked long hours; for her children, who lived and worked locally; and for her baby grandchild, who, as part of a care order, spent significant amounts of time with her during the day. On Sundays, she felt that it was her duty to cook a roast dinner for them all and was determined that she would continue to do this. Another aspect to her determination was her personal recognition that occupation was central to her mental health, having had long-term experience of mental health problems. Her statement that the kitchen as it stood was driving her crazy was based on a significant fear of losing her mental health again. How could I, as her social services occupational therapist, enable her to manage her fears and accept that delay, however undesirable, was inevitable in this situation?

\section{Nelson's definition of therapeutic occupation}

Central to Nelson's (1996) model is the individual, who engages in occupations (occupational performance) with a sense of purpose. The impact of this activity is demonstrated by an external change in the environment (occupational form), which has meaning for the individual. The effect of occupational therapy is represented by 'occupational synthesis'. The occupational therapist perceives the occupational performance, knows the occupational form and understands the person. This synthesis enables the design of a 'just right challenge' (Csikszentmihalyi 1992), where an optimum situation is set up by the occupational therapist and the person to facilitate change. This, in turn, links with the concept of flow and how this is associated with profound personal change through engaging with just right challenges (Emerson 1998).

It could be argued that Nelson's (1996) model is essentially a model dividing human occupation into component parts and, as such, possibly has the same limitations for relevance to practice as other models. However, the model places equal emphasis on the relations between the components, embodied in the terms 'impact', 'purpose' and 'meaning'.
The sense of movement between the components, indicated clearly for the occupational therapist, suggests that this model not only is applicable to complex clinical situations but also could enhance understanding.

Nelson's (1996) model also shows potential for being combined with narrative reasoning to explain Patricia's situation (Mattingly and Fleming 1994). There is a simple overview: Patricia, with mobility problems arising from chronic back pain, moves into a house where the kitchen is largely inaccessible. Occupational therapy is required to evaluate her needs and recommend adaptations. Fine-tuning of the adaptations occurs through continuing service user contact. A wider picture of the meaning of the kitchen for her as an individual guides the complex process of both adapting her house and explaining her response.

Incorporated in the narrative is the past and the present, with an ever-changing image of the future. A sense of both Patricia's past and her anxieties about the future is revealed.

\section{- The person}

Patricia, being a mother and a grandmother, had a vivid sense of her own personal history. She was intolerant of restrictions on her life having experienced them too much in the past, especially in an earlier relationship which she experienced as violent and unstable. Caring for her extended family was a positive role for her, with practical implications for her everyday life.

\section{- The purpose}

Patricia found that making meals in her new kitchen was practically impossible. She was anxious to change it as soon as possible.

\section{- Occupational performance}

Patricia demonstrated how difficult it was for her to reach the high cupboards. She could not transfer hot items from the microwave oven because there were no worktops.

\section{- Impact on occupational form}

Patricia had chosen to make the main entry to the house via the kitchen door. On arrival, it was difficult to ignore the chaos in the kitchen, indicative of Patricia's efforts to cook meals in it. A large pantry cupboard took a disproportionate amount of space and the floor was stacked with tins of food because the shelves were too high to reach.

\section{- Meaning}

As time progressed and bureaucratic delays continued, the meaning of the kitchen changed for Patricia. Initially, instilled with a sense of the potential of her new home, she was positive. Her anger grew as the delays continued and she began to hate the kitchen.

\section{- Occupational synthesis}

This could be described as the occupational therapist knowing that Patricia (the person) had limited tolerance for frustrating situations; seeing her difficulty in maintaining her role as meal provider (occupational performance); and understanding the inevitable delays in 
implementing the recommended adaptations

(occupational form). There were a number of strategies available to help her to manage the situation, although not many were available in the context of social services occupational therapy provision. At one point, when the temporary absence of her grandchild was causing great concern, an attempt to help Patricia to look beyond her occupations in the kitchen and the house was made. She seized on this opportunity briefly, considering what she could go out and do instead of remaining at home. This would link with Nelson's (1996) concept of a 'substitute occupational performance'.

Nelson (1996) also distinguished between adaptation and compensation. Occupational adaptation involves regaining or learning the skills necessary for a particular purpose. Occupational compensation involves finding alternative ways round a problem. Adaptation may be required to achieve occupational compensation; for example, Patricia could have learned to manage her frustration using a cognitive behavioural approach and engaged in alternative occupations beyond her home. An integrated approach between community mental health occupational therapists and social services occupational therapists facilitates such changes and fulfils Nelson's (1996, p780) belief that 'occupational synthesis is a powerful tool in health promotion and disease prevention'.

\section{Occupational science and occupational therapy}

Along with my colleagues, at times I questioned the legitimacy of recommendations such as those to adapt Patricia's kitchen. Were these adaptations a priority for funding? The questioning was from an organisational perspective, rather than from the service user's perspective. The argument that her mental health would be adversely affected, by the frustration of not being able to perform her role as family cook, was incorporated into reports but not emphasised initially. It could be argued that counselling might help her to adapt to her limitations and to accept that being active in the kitchen was no longer possible. But she knew that she could do it, given the right environment or occupational form, as in Nelson's (1996) model. And she knew that she had to do it, for her sanity. Tamm's (1999) study of the meaning of the home also emphasised how the presence of professionals in the home precipitated fears of loss of control.

The ageing process, when viewed from an occupational perspective, illuminates human strategies for adaptation to change. The study by Pentland et al (1999), involving women with physical disabilities and investigating the impact of ageing on occupational behaviour, indicated that those who coped more successfully were doing so by redefining their expectations and engaging in less physical occupations. Occupational therapists are often in contact with people who find adapting to change difficult and the therapists are required to create opportunities for them to move forwards, with support (Melton 1998, Hasselkus 1998). It is possible that occupational therapists who feel that their role is traditionally constrained by the occupational therapy process as a basic theory may be liberated to work more creatively by the emerging findings of occupational science.

\section{Occupational therapy: a synthesis of art and science?}

It has been suggested by Frank (1996) that occupational science could be described as 'applied moral philosophy' as much as a 'social science'. However, the emphasis on finding general rules and definitions would suggest a basis in science because, as Zemke and Clark (1996) suggest, being open to public scrutiny and producing results that can be replicated are key aspects of science. Choosing which aspects of occupation to research into is a subjective process, reflecting contemporary cultural concerns as well as personal ones. Research, after all, is itself an occupation.

Bateson (1996) argued that understanding the complexities of occupation is an art and that separating out the meaning of occupations is not always possible, especially in relation to women's lives. Any static theory will have limited application to a situation as complex and fluid as encountered by an occupational therapist in social services. Changes within and beyond the therapeutic session are elusive when under scrutiny. The essence of art is a unique result every time: outcomes cannot be guaranteed with the use of a particular method. Appreciation of the created object is enhanced by an understanding of its context and that understanding is in a constant state of development with each new appraisal.

Perks (1998) argued that the Western preoccupation with the purpose of activity should be balanced with an intuitive approach, rooted in Eastern culture. Constant awareness of the significance of an occupation distracts attention from the occupation in progress. The theories of occupation appear to be most useful in clinical practice when they can be combined with clinical reasoning theories, which is presumably why Kielhofner (1997) sought to incorporate narrative reasoning theories into his model of human occupation. A knowledge of clinical reasoning theories gives a structure for the occupational therapist in the clinical setting to access thought processes, which influence decisions. Integrating the findings of science with the art of practice is a continuing challenge.

\section{Conclusion}

What part did art and science play in planning the new kitchens?

The creation of a narrative is an art: emphasising parts of the planning and playing down others, creating suspense, encouraging the audience to listen and anticipating the ending. Why is a new kitchen created at a particular time by particular people? The reasons are inevitably a unique 
combination of personal opportunities in a cultural context Similarly, the occupational therapist, seeking to make sense of a service user's situation, needs to create an image, a narrative, of how things are now and how they could be in the future. This reflects approaches to kitchen design and alteration used in the commercial world. Creating a profile of the situation, and revising it as time passes and interventions begin to have an impact, is a process demanding thought and attention.

Matching what is seen in each clinical situation to what has been experienced before, whether by the therapist herself or vicariously, requires clarity of thought. The complexity needs unravelling and elements of the situation need to be investigated. The combination of problems may be unique, but not each single component in itself. The difficulty in reaching high cupboards is common and easily remedied by lowering them. Science enables us to reproduce the methods used before with predictable results. The Canadian Model of Occupational Performance could be used to understand every person encountered. Choosing the right standardised assessment instrument could enable specific information to be gained in a systematic way.

So the occupational therapist could look to science to inform the assessment and interpretation of situations. A structure could be built up to manage information and a language developed that is understood by others. In essence, the same conclusion might be reached by a number of therapists as a result of scientific investigation. For the service user, this could guarantee a certain level of quality and uniformity within the service provided.

In promoting uniformity and quality, however, there might be a risk that individual differences are lost. In the domestic arena, individuality is far more important than adherence to a general rule, especially beyond basic concerns of safety and survival. Creativity in the occupational therapist as facilitator is essential to enable the service user to express his or her individuality and to facilitate problem solving. Occupational theories can inform the work of occupational therapists in the community, but the interpretation of each situation and facilitation of subsequent change is the art of practice.

\section{Acknowledgements}

The first author would like to thank all those who contributed to her learning. This paper is based on work submitted in part fulfilment for the MScOT at Brunel University.

\section{References}

Bateson M (1996) Enfolded activity and the concept of occupation. In:

R Zemke, F Clark, eds. Occupational science: the evolving discipline. Philadelphia: FA Davis.

Bolton G (2001) Reflective practice: writing and professional development. London: Paul Chapman.

Campbell J (2002) Valuing diversity: the disability agenda - we've only just begun. Disability and Society, 17(4), 471-78.

Canadian Association of Occupational Therapists (1997) Enabling occupation: an occupational therapy perspective. Ontario: CAOT Publications ACE.
Community Occupational Therapy Services (1999) Report of Conference Programme: Linking the thinking - integrating practices. London: Department of Health.

Creek J (1998) Purposeful activity. In: J Creek, ed. Occupational therapy: new perspectives. London: Whurr, 16-28.

Creek J (2003) A definition of occupational therapy as a complex intervention. London: College of Occupational Therapists.

Csikszentmihalyi M (1992) Flow. London: Rider.

Emerson H (1998) Flow and occupation: a review of the literature. Canadian Journal of Occupational Therapy, 65(1), 37-44.

Frank $G$ (1996) The concept of adaptation as a foundation for occupational science research. In: R Zemke, F Clark, eds. Occupational science: the evolving discipline. Philadelphia: FA Davis.

Golledge J (1998) Distinguishing between occupation, purposeful activity and activity, part 1: review and explanation. British Journal of Occupational Therapy, 61(3), 100-105.

Harvey A, Pentland W (2004) What do people do? In: C Christiansen, E Townsend, eds. Introduction to occupation: the art and science of living. Englewood Cliffs, NJ: Prentice Hall, 63-90.

Hasselkus B (1998) Occupation and well-being in dementia: the experience of day-care staff. American Journal of Occupational Therapy, 52(6), 423-34.

Hasselkus B (2002) The meaning of everyday occupations. Thorofare, NJ: Slack.

Hocking C (2000) Occupational science: a stock take of accumulated insights. Journal of Occupational Science, 7(2), 58-67.

Kielhofner $\mathrm{G}$ (1997) Conceptual foundations of occupational therapy. 2nd ed. Philadephia: FA Davis, 187-217.

Mattingly C, Fleming M (1994) Clinical reasoning: forms of inquiry in a therapeutic practice. Philadelphia: FA Davis.

McColl MA (2003) The occupational therapy toolbox: uses of theory in occupational therapy. In: MA McColl, MC Law, L Doubt, N Pollock, D Steward, eds. Theoretical basis of occupational therapy. 2nd ed. Thorofare, NJ: Slack, 7-10.

Melton J (1998) How do clients with learning disabilities evaluate their experience of cooking with the occupational therapist? British Journal of Occupational Therapy, 61(3), 106-10.

Nelson D (1996) Therapeutic occupation: a definition. American Journal of Occupational Therapy, 50(10), 775-82.

Oliver M (1999) Social work with disabled people. Basingstoke: Macmillan.

Pentland W, Tremblay M, Spring K, Rosenthal C (1999) Women with physical disabilities: occupational impacts of ageing. Journal of Occupational Science, 6(3), 111-23.

Perks M (1998) Oil and water. In: J Creek, ed. Occupational therapy: new perspectives. London: Whurr, 142-55.

Polgar J, Landry J (2004) Occupations as a means for individual and group participation in life. In: C Christiansen, E Townsend, eds. Introduction to occupation: the art and science of living. Englewood Cliffs, NJ: Prentice Hall, 197-220.

Porter J, Watson G, Capra S (1998) Food skills assessment tools for people with a mental illness. Australian Journal of Occupational Therapy, 45(2), 65-71.

Primeau L (1996) Work versus nonwork: the case of household work. In: R Zemke, F Clark, eds. Occupational science: the evolving discipline. Philadelphia: FA Davis.

Reilly M (1962) Occupational therapy can be one of the great ideas of 20th century medicine. American Journal of Occupational Therapy, $16,1-9$. 
Rigby P, Letts L (2003) Environment and occupational performance: theoretical considerations. In: L Letts, P Rigby, D Stewart, eds. Using environments to enable occupational performance. Thorofare, NJ: Slack, 17-32.

Ruskin J (1907/2000) Sesame and lilies. Facsimile edition. Lancashire: Hendon Publishing.

Stark S (2003) Home modifications that enable occupational performance. In: L Letts, P Rigby, D Stewart, eds. Using environments to enable occupational performance. Thorofare, NJ: Slack, 219-34.

Stewart D, Law M (2003) The environment: paradigms and practice in health, occupational therapy and inquiry. In: L Letts, P Rigby, D Stewart, eds. Using environments to enable occupational performance. Thorofare, NJ: Slack, 3-15.

Tamm M (1999) What does a home mean and when does it cease to be a home? Home as a setting for rehabilitation and care. Disability and Rehabilitation, 21(2), 49-55.

Tregaskis C (2002) Social Model Theory: the story so far... Disability and Society, 17(4), 457-70.
Whiteford G (2000) Occupational deprivation: global challenge in the new millennium. British Journal of Occupational Therapy, 63(5), 200-204.

Wilcock A (1998) An occupational perspective of health. Thorofare, NJ: Slack, 24, 89.

Yerxa $\mathrm{E}$ (2000) Confessions of an occupational therapist who became a detective. British Journal of Occupational Therapy, 63(5), 192-99.

Zemke R, Clark F, eds (1996) Occupational science: the evolving discipline. Philadelphia: FA Davis.

\section{Authors}

Wendy Bryant, DipCOT, MSc, Occupational Therapy Lecturer, School of Health Sciences and Social Care, Brunel University, Osterley Campus, Borough Road, Isleworth, Middlesex TW7 5DU. Email:Wendy.Bryant@brunel.ac.uk

Elizabeth McKay, PhD, MSc, BSc(Hons), DipCOT, ILTM, Head, Department of Occupational Therapy, School of Health Sciences, University of Limerick, Ireland. 